\title{
ON A HILBERT-TYPE INTEGRAL INEQUALITY WITH NON-HOMOGENEOUS KERNEL OF MIXED HYPERBOLIC FUNCTIONS
}

\author{
Minghui You And Yue GuAN
}

\begin{abstract}
In this paper, by constructing a new non-homogeneous kernel of mixed hyperbolic functions, we establish a new Hilbert-type integral inequality with the best constant factor. We also consider the equivalent form of the obtained inequality. Moreover, by using the rational fraction expansion of cotangent function and cosecant function, some special Hilbert's type inequalities with the constant factors related to the higher derivatives of cotangent function and cosecant function are presented.
\end{abstract}

Mathematics subject classification (2010): 26D15,41A17. function.

Keywords and phrases: Hilbert-type inequality; hyperbolic function; rational fraction expansion; $\Gamma$ -

\section{REFERENCES}

[1] V. Adiyasuren, T. BAtBold B, M. KRnić, Half-discrete Hilbert-type inequalities with mean operators, the best constants, and applications, Applied Mathematics and Computation. 231(2014), 148159.

[2] G. H. Hardy, J. E. Littlewood, G. Pólya, Inequalities, Cambridge Univ. Press, London, 1952.

[3] J. Jin, L. Debnath, On a Hilbert-type linear series operator and its applications, J. Math. Anal. Appl. 371(2010), 691-704.

[4] M. Krnić, J. PeČArić, Extension of Hilbert's inequality, J. Math. Anal. Appl. 324(2006), 150-160.

[5] M. KRniĆ, J. PeČARIĆ, P. VUKOVIĆ, Discrete Hilbert-type inequalities with general homogeneous kernels, Rend. Circ. Mat. Palermo 60(2011), 161-171.

[6] M. Krnić, J. PeČArić, I. Perić, P. Vuković, Renct advances in Hilbert-type inequalities, Element Press, Zagreb, 2012.

[7] M. KRnić, J. PeČARIć, General Hilbert's and Hardy's inequalities, Math. Inequal. Appl. 8(2005), $29-51$.

[8] J. Kuang, L. Debnath, On new generalizations of Hilbert's inequality and their applications, J. Math. Anal. Appl. 245(2000), 248-265.

[9] J. PeČARIĆ, P. Vuković, Hardy-Hilbert-type inequalities with a homogeneous kernel in discrete case, J. of inequal. and appl. vol. 2010, Article ID 912601, 8pages, 2010.

[10] Michael Th. Rassias, B. YAnG, A Hilbert-type integral inequality in the whole plane related to the hypergeometric function and the beta function, J. Math. Anal. Appl. 428(2015), 1286-1308.

[11] Z. WANG, D. Guo, Introduction to Special Functions, Higher Education Press, Beijing, 2012.

[12] B. YANG, On New Generalizations of Hilbert's Inequality, J. Math. Anal. Appl. 248(2000), 29-40.

[13] B. YAng, The Norm of Operator and Hilbert-Type Inequalities, Science Press, Beijing, 2009.

[14] B. YANG, M. KRnić, On the norm of a multidimensional Hilbert-type operator, Sarajevo J. Math. 20(2011), 223-243. 